\title{
Increased Neuronal Endocytosis and Protease Delivery to Early Endosomes in Sporadic Alzheimer's Disease: Neuropathologic Evidence for a Mechanism of Increased $\beta$-Amyloidogenesis
}

\author{
Anne M. Cataldo, ${ }^{1,2}$ Jody L. Barnett, ${ }^{1}$ Cristiana Pieroni, ${ }^{1}$ and Ralph A. Nixon ${ }^{1,2,3}$ \\ 1 Laboratories for Molecular Neuroscience, McLean Hospital, Belmont, Massachusetts 02178, ${ }^{2}$ Departments of \\ Psychiatry and Neuropathology, and 3Program in Neuroscience, Harvard Medical School, \\ Belmont, Massachusetts 02178
}

\begin{abstract}
The early endosome is the first vacuolar compartment along the endocytic pathway. It is the site of internalization and initial processing of amyloid precursor protein (APP) and apolipoprotein $E(A p o E)$, two proteins of etiological importance in Alzheimer's disease, and a putative site of $\beta$-amyloid peptide $(A \beta)$ formation. Here, we identify early endosomes in human pyramidal neurons, using specific compartmental markers and morphometry, and show that in Alzheimer's disease individual endosomes display up to 32-fold larger volumes than the normal average. Endosomal enlargement contributed to an average 2.5-fold larger total endosomal volume per neuron, implying a marked increase in endocytic activity. Endosomal alterations were evident in most pyramidal neurons in Alzheimer brain, detectable at early stages of the disease but absent in several other neurodegenerative disorders examined. In addition, ma-
\end{abstract}

ture and proenzyme forms of the proteases cathepsin $B$ and cathepsin D, a candidate APP secretase, were identified in most early endosomes in Alzheimer brains but were detectable in only a minor proportion of endosomes in normal brain. Expression of the cation-dependent $46 \mathrm{kDa}$ mannose 6-phosphate receptor was elevated in pyramidal neurons of Alzheimer brains, which could be a possible basis for the altered cathepsin trafficking pattern. Enhanced endocytic activity, coupled with increased trafficking to endosomes of proteases, which may have the ability under pathological conditions to generate $A \beta$, constitutes a potential mechanism by which $\beta$-amyloidogenesis may become accelerated in sporadic $A D$ and also be subject to influences by ApoE.

Key words: endocytosis; early endosome; protease; neurodegenerative disease; $\beta$-amyloidogenesis; lysosomal trafficking
The neuronal endocytic pathway is a finely controlled and efficient intracellular trafficking system for internalizing and processing extracellular nutrients and trophic factors, for recycling or catabolizing receptors and other integral membrane proteins after neurotransmitter release, and for directing information to intracellular biosynthetic pathways. Endocytosis enables cells to modify or degrade molecules within a continuum of morphologically and biochemically distinct vacuolar compartments. These compartments include early and late endosomes and lysosomes, which have different capabilities for processing substrates by proteolysis (Diment et al., 1989; Casciola-Rosen and Hubbard, 1991; Berg et al., 1995). A variety of acid hydrolases is packaged within the Golgi apparatus and then trafficked by shuttle vesicles to these compartments under the regulation of cation-dependent and cation-independent mannose 6-phosphate receptors (MP-R). The turnover of endocytosed materials originally was thought to be limited to lysosomes, but it is known now that in certain non-neuronal cells some acid proteases may be present in endo-

Received Dec. 11, 1996; revised May 20, 1997; accepted May 23, 1997.

This project was supported by Public Health Service Grant 5R35 AG10916-05 to R.A.N. and Grant MH/NS31862 (Harvard Brain Tissue Resource Center). We thank Maureen Medeiros for secretarial assistance and Lisa Kanaley-Andrews for technical expertise. Affinity-purified antiserum directed against the $215 \mathrm{kDa}$ mannose 6-phosphate receptor (MP-R) was a generous gift from Dr. Stuart Kornfeld. Antibodies directed against the cation-dependent $46 \mathrm{kDa}$ MP-R were kindly provided by Drs. Kurt von Figura and Annette Reyfeld.

Correspondence should be addressed to Dr. Anne M. Cataldo, Nathan Kline Institute for Psychiatry, New York University School of Medicine, 140 Old Orangeburg Road, Orangeburg, NY 10962.

Copyright (C) 1997 Society for Neuroscience $0270-6474 / 97 / 176142-\bullet \$ 05.00 / 0$ somes and can modify endocytosed proteins (Diment et al., 1989; Casciola-Rosen and Hubbard, 1991; Berg et al., 1995).

Interest in the neuronal endosomal-lysosomal (E-L) system and in the processing enzymes residing in its acidic compartments has grown recently because of the pathophysiological importance of this system in Alzheimer's disease (AD). Proteins closely linked to AD pathogenesis, such as altered amyloid precursor protein (APP), the $\beta$-amyloid protein $(\mathrm{A} \beta)$, and apolipoprotein $\mathrm{E}$ $(\mathrm{ApoE})$, are internalized and processed within the E-L system. The E-L system, therefore, represents a shared cellular pathway in which these etiological influences may converge. Our previous studies (Nixon and Cataldo, 1993; Cataldo et al., 1995, 1996) of AD brain revealed a marked upregulation of lysosomal activity at an early stage in the metabolic compromise of neurons within affected regions, including marked upregulation of acid hydrolase synthesis and two- to sevenfold increases in the numbers of lysosomes. The accumulation of various acid hydrolases within late endosomes and lysosomes, including proteases with potential APP secretase activities such as cathepsins B and D (Tagawa et al., 1991; Nixon and Cataldo, 1993; Dreyer et al., 1994; Cataldo et al., 1995, 1996; Evin et al., 1995), the release of these enzymes after neuronal lysis (Nixon and Cataldo, 1993; Cataldo et al., 1994, 1995, 1996), and their persistence extracellularly in association with $\mathrm{A} \beta$ deposits (Nixon and Cataldo, 1993; Cataldo et al., $1994,1995,1996)$, has been observed only in disorders in which $\mathrm{A} \beta$ is accumulated, suggesting a link between $\mathrm{E}-\mathrm{L}$ system abnormalities and $\beta$-amyloidogenesis.

In this study we used immunocytochemical and morphometric approaches to identify neuronal early endosomes for the first time 
in situ. We used an antibody to rab5, the monomeric GTP-binding protein that modulates transport kinetics between the plasma membrane and early endosomes (Gorvel et al., 1991; Bucci et al., 1992; de Hoop et al., 1994), to label specifically the early endosomes. In cultured non-neuronal and neuronal cells, rab5 is localized selectively to early endosomes and, to a lesser extent, clathrincoated vesicles and the plasmalemma. Immunocytochemical markers of late endosomes (cation-independent $215 \mathrm{kDa}$ MP-R) and lysosomes [acid hydrolases and lysosome-associated membrane proteins (LAMPs)] used in our previous studies (Cataldo et al., 1996), as well as cellular size and location criteria, enabled us to distinguish among the major acidic compartments that make up the E-L system. In doing this, we identified striking alterations in the size and volume of early endosomal compartments in neurons of affected regions of AD brains, as well as in the localization pattern of acid hydrolases, in both their pro- and mature forms within these same compartments. These results, which support upregulation of endocytosis and increased hydrolase delivery to early endosomes in neurons of vulnerable regions of AD brains, suggest how $\beta$-amyloidogenesis may be initiated in the early endocytic pathway and how ApoE may exert its influence on AD pathogenesis.

\section{MATERIALS AND METHODS}

Tissue. Postmortem brain tissue from nine individuals with the probable clinical diagnosis of AD and eight age-matched 62- to 78-year-old neurologically normal controls were used in this study. Tissue was procured from the Harvard Brain Tissue Resource Center at McLean Hospital (Belmont, MA) and the Neuropathology Core Facility of the Massachusetts Alzheimer's Disease Research Center (Massachusetts General Hospital, Boston, MA). Control brains exhibited minimal histopathological changes $(0-3$ neuritic plaques/low power field; $0-6$ neurofibrillary tangles/low power field). The presence and magnitude of neurodegeneration and neurofibrillary histopathology were confirmed with the use of Nissl and Bielschowsky stains, and the diagnosis of AD was established by criteria from the Consortium to Establish a Registry for Alzheimer's Disease (Mirra et al., 1991). Brain tissue used for immunocytochemical analyses was immersion-fixed in cold $10 \%$ phosphate-buffered $(0.15 \mathrm{M})$ formalin, $\mathrm{pH}$ 7.4. The postmortem interval for all brain tissue was $\leq 6 \mathrm{hr}$, with a total fixation time of 2 weeks or less.

Antibodies. Immunocytochemical studies were performed with antibodies to the two lysosomal hydrolases, cathepsin D (Cat D) and cathepsin B (Cat B), and the rab-related GTP-binding protein rab5. Anti-Cat $\mathrm{D}$ antiserum was prepared in our laboratory and raised in sheep against human brain Cat D (Nixon and Marotta, 1984; Cataldo et al., 1990). Human liver anti-Cat B antiserum was purchased commercially from ICN Biochemicals (Costa Mesa, CA). The anti-pro-Cat D antiserum was purchased commercially from Oncogene Science (Cambridge, MA). Antibody directed against rab5 is a commercially prepared affinitypurified rabbit polyclonal antibody (Santa Cruz Biotechnology, Santa Cruz, CA) raised against a synthetic peptide corresponding to amino acids 193-211 of the C-terminal domain of human rab5. An affinitypurified rabbit polyclonal antibody directed against the cytoplasmic tail of human $46 \mathrm{kDa}$ MP-R was generously provided by Drs. Kurt von Figura and Annette Reyfeld, Georg-August-Universitat, Göttingen, Germany (Stein et al., 1987a; Nadimpalli et al., 1991).

Immunocytochemistry. Immunoreactivity was demonstrated on 30- to 40- $\mu \mathrm{m}$-thick vibratome sections, as previously described (Cataldo et al., 1990). Negative controls consisted of tissue sections incubated in preimmune antisera or in the absence of primary antisera. For immunofluorescence studies sections were double-immunostained with different hydrolase antisera and rab5, and immunoreactivity was demonstrated with secondary antibodies conjugated to FITC, TRITC, or Texas Red (Cataldo et al., 1990, 1996).

Digital confocal analysis. High-resolution images of double-labeled neurons were viewed at high magnification with digital confocal microscopy. Images were created from representative neurons that displayed both $\mathrm{C}$ at $\mathrm{D}$ or $\mathrm{Cat} \mathrm{B}$ and rab5 immunofluorescence. Digital images were obtained as previously reported (Cataldo et al., 1996). A Z-series stack of high-magnification digitized images of representative neocortical layer III pyramidal neurons was acquired through consecutive focal planes
(Cataldo et al., 1996). For each single- and double-labeled neuron, two Z-series stacks were generated with FITC and TRITC filters, respectively. Parallel pairs of stacks were processed with a deconvolution subroutine of the BDS-IMAGE software, and images displaying the colocalization of each fluoroprobe were generated by the Multicolor Registration subroutine (BDS-IMAGE software).

Morphometric analysis. Vibratome sections from the prefrontal cortices of eight age-matched controls and nine AD brains were immunostained in tandem under identical experimental conditions with rab5 antiserum. Background staining intensities between $\mathrm{AD}$ and control sections were comparable in all cases, and all neurons were intact. Small, medium, and large pyramidal neurons from cortical laminae III were selected at random (Cataldo et al., 1996). The cross-sectional area, number of endosomes, average endosomal volume, and total early endosomal volume per cell were analyzed for each neuron by the Bioquant System IV morphometry software package (R \& M Biometrics, Nashville, TN) at $1000 \times$ magnification. Counts of rab5-positive endosomes were made by direct inspection in a single plane of focus. To measure cross-sectional areas, we used a Leitz microscope with a low-light video camera attachment to capture and display high-resolution images by a Targa frame grabber. Neurons were isolated and outlined with a Summagraphics digitizing tablet. For each brain 25 neurons were assessed at random within several fields from neocortical layer III. In total, 200 neurons from the control and 225 neurons from the AD cases were analyzed. For statistical comparisons based on endosomal size, each endosome was assigned to one of four groups on the basis of volume: (in $\mu \mathrm{m}^{3}$ ) $0-0.35$, $0.35-1.0,1.0-2.1,2.1-7+\mu \mathrm{m}$. All data sets examined showed nonparametric distributions. ANOVA with the Kruskal-Wallis test $(p<0.05)$ showed significant differences between the Alzheimer and control groups analyzed. The Tukey-Kramer test $(p>0)$ was used to demonstrate statistically significant differences in total endosomal volume and individual endosomal size per cell between Alzheimer and control groups.

Vibratome sections from the prefrontal cortices of six control brains and seven age-matched AD brains were immunostained in tandem under identical experimental conditions with anti-MP-R46 antiserum. It should be noted that the background staining intensities between $A D$ and control sections were comparable in all cases and that all neurons counted were intact. Small, medium, and large pyramidal neurons from lamina III were selected at random, using a $100 \times$ oil immersion objective (N.A. 1.518). The cross-sectional area and MP-R density were analyzed for each of 25 neurons, as previously described (Cataldo et al., 1996). The image system was calibrated by placing an image box over the laminae of interest and recording the optical density [expressed as 0-255 levels of gray scale: 0, lowest density; 255, highest density (Cataldo et al., 1995)].

For statistical comparisons based on cell size, each neuron was assigned to one of three groups on the basis of a real diameter: $0-150$, 151-225, and $>225 \mu \mathrm{m}^{2}$. All data sets examined showed parametric distribution. Statistical computations were performed with a Student's $t$ test.

\section{RESULTS}

\section{Rab5-positive early endosomes are a distinct group of hydrolase-containing organelles in human neurons}

In tissue sections of human neocortex from normal individuals, anti-rab5 antiserum immunolabeled a population of small neuronal vacuolar compartments distributed close to the plasmalemma. This localization is distinct from either the predominantly perinuclear distribution of late endosomes, the uniform cytoplasmic distribution of lysosomes (Fig. 1), or the basal location of lipopigment granules. Rab5-positive early endosomes were spherical in shape and relatively uniform in size (100-250 nm), similar to those described in non-neuronal cell types (Gorvel et al., 1991; Bucci et al., 1992, 1994; de Hoop et al., 1994). They were most numerous in the soma and proximal dendrites. As shown in our previous studies, antibodies to 215 $\mathrm{kDa}$ MP-R selectively immunolabeled late endosomes and distinguished these compartments from MP-R-negative lysosomes (Fig. 1), which comprise the major subpopulation of acid hydrolase-containing organelles. In neurons from aged control brains, late endosomes and lysosomes typically displayed di- 

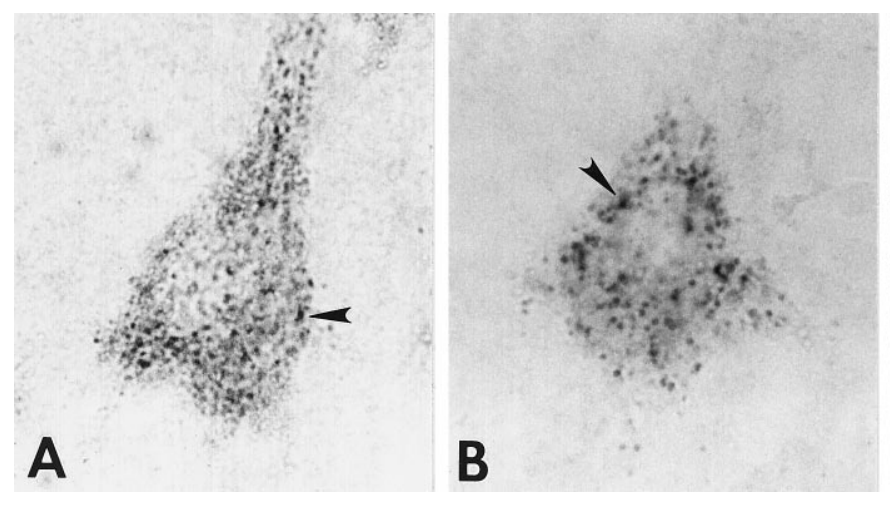

ameters ranging from 100 to $400 \mathrm{~nm}$ and from 50 to $400 \mathrm{~nm}$ (Nixon and Cataldo, 1995), respectively. Rab5 was absent from lipof uscin granules, which were identified on the basis of size $(0.5-1.5 \mu \mathrm{m})$, the presence of autofluorescent lipopigment, and a concentration within the basal pole of the cell soma.

\section{Early endosomes in neurons of $A D$ brain are abnormally large}

We found a striking difference in the morphology of rab5-positive early endosomes in pyramids of at-risk neocortical regions of AD brains, as compared with that of early endosomes in control regions (Fig. 2). Pyramidal neurons in lamina III of the prefrontal cortex exhibited atypically large early endosomes resembling the ones seen in baby hamster kidney (BHK) cells when the wild-type rab5 protein (Bucci et al., 1992) was overexpressed to stimulate endocytosis. In addition to being rab5-immunoreactive, the large early endosomes were distinguished from MP-R-positive, rab5negative late endosomes and rab-negative, MP-R-negative lysosomes on the basis of size. Early endosomes in AD brains measured an average of $487 \mathrm{~nm}$ in diameter (average diameter per brain ranged from 400 to $620 \mathrm{~nm}$ ), whereas late endosomes and lysosomes were consistently no larger than $400 \mathrm{~nm}$ in diameter. Large early endosomal profiles were found principally in at-risk pyramids of laminae III and V. In the less vulnerable neurons of laminae II and IV, the sizes of rab5-positive endosomes in small- to medium-sized pyramidal neurons, nonpyramidal neurons, and glia were equivalent to those in controls.

The size and/or number of early endosomes in neuronal and non-neuronal animal cells have been shown in vivo and in vitro to be proportional to the rate of endocytic uptake (Parton et al., 1989, 1992; Stenmark et al., 1994). Therefore, to index this neuronal endocytic function, we used computerized morphometry to determine the number and volumes of rab5-immunoreactive compartments in 25 pyramidal neurons from lamina III of the prefrontal cortex in each of nine AD and eight age-matched control brains (Fig. 2). Total numbers of early endosomes in neurons from AD
Figure 1. Identification of early endosomes as distinct hydrolase-containing compartments in human pyramidal neurons. $A$, Consistent with established morphological criteria, rab5-positive early endosomes (arrowhead) in cortical pyramids of aged control human brain were distributed close to the plasmalemma and were relatively uniform in size. Immunoreactive endosomes were located principally in the soma and proximal dendrites. We have shown that these structures represent a subpopulation of neuronal acid-hydrolasecontaining compartments (see Fig. 3). $B$, We distinguished early endosomal compartments from a smaller subgroup of hydrolase-containing, rab5-negative, MP-R215-positive late endosomes (arrowhead) that displayed the typical perinuclear distribution. $C$, Lysosomes, which contain Cat D (arrow) and a number of other hydrolases, are MP-Rnegative, rab5-negative, and distinct from early and late endosomes. Lysosomes, which comprise the major population of acidic vacuolar compartments, are typically $50-400 \mathrm{~nm}$ in diameter and are distributed uniformly throughout the cytosol. Magnification in $A-C$, $4500 \times)$. brains were markedly similar to those in neurons from control brains (AD average, 49 endosomes/cell; control average, 58 endosomes/cells). Of the neocortical pyramids in lamina III of AD brain, $48 \%$ had abnormally large endosomal volumes (i.e., total endosome volume $>1$ SD higher than the control mean). The percentage of cell area occupied by rab5-positive early endosomes averaged 2.5-fold greater $(p<0.0001)$ in the pyramidal neurons of the AD brains than in controls $(\mathrm{AD}$ mean $=5.37 \% \pm 0.19$; control mean $=2.18 \% \pm 0.09)($ Fig. $2 C)-\mathrm{a}$ finding consistent with an upregulation of endocytosis (Parton et al., 1989, 1992; Gorvel et al., 1991; Bucci et al., 1992, 1994; Stenmark et al., 1994). Substantial numbers of individual endosomes were eightfold to 32-fold larger than the average size of endosomes in control neurons (Fig. 2D). The incidence of abnormally large early endosomes $\left(>1 \mu \mathrm{m}^{3}\right)$ was $\sim$ ten-fold higher in AD brains than in controls (AD mean $=7.80$ \pm 1.65 ; control mean $=0.80 \pm 0.13 ; p<0.0001$ ) (Fig. $2 E$ ). Similar abnormalities were detected in neuronal pyramids from lamina $\mathrm{V}$ (data not shown). By contrast, cell size in neuronal populations within severely affected regions from cases of Pick's disease, Huntington's disease (grades 0-3), diffuse Lewy body disease, progressive supranuclear palsy, or encephalitis fell within the normal control range.

\section{Immature and mature lysosomal proteases frequently are detected in the early endosomes of neurons in AD}

Because early endosomes normally may contain low levels of acid hydrolases and because cathepsin expression is markedly upregulated in AD brain (Nixon and Cataldo, 1993, 1995; Cataldo et al., 1994, 1995, 1996), we evaluated whether the delivery of cathepsins to early endosomes may be increased in AD. As we reported previously (Nixon and Cataldo, 1993, 1995; Cataldo et al., 1994, 1995, 1996), most pyramidal neurons of laminae III and V of AD brains exhibited increased numbers of hydrolase-positive compartments. Confocal immunofluorescence image analyses of human brain sections double-labeled with antibodies to rab5 and to the mature form of $\mathrm{Cat} \mathrm{D}$ or to rab5 and to mature Cat $\mathrm{B}$ 
Figure 2. Morphometric analysis of rab5-positive early endosomes in control and Alzheimer's disease (AD) brains. High-magnification images of early endosomal compartments (arrows) in neocortical neurons in lamina III of aged control $(A)$ and $\mathrm{AD}(B)$ brains immunostained with rab5 and enhanced by Nomarski optics show the striking increase in the size of these compartments in AD brain, as compared with control. In some, invaginations suggest a location at the plasmalemma. $C$, Percentage of cell area occupied by rab5positive early endosomes plotted as a function of total cell area. Alterations in early endosomes were widespread in AD brains, and many pyramidal neurons in AD brains (filled triangles) exhibited a significant increase $(>2$ SD higher than the control mean) in total endosomal volume per cross-sectional cell area as compared with age-matched controls (open circles) (AD mean = $5.37 \% \pm 0.19 ;$ control mean $=2.18 \% \pm$ $0.09)$. $D$, The size distributions of individual early endosomes present in 25 lamina III pyramids from each of eight aged control and nine AD brains show that a substantial proportion of individual neuronal endosomes in the AD brains had volumes larger than those in control brains. Endosomal volume is expressed as a function of cell area for easier visualization of data. $E$, The percentage of abnormally large endosomal profiles that are $>1 \mu \mathrm{m}^{3}$. Values are mean percentage based on 25 pyramidal neurons per individual brain $(n=$ $9 \mathrm{AD}$ and 8 controls). Approximately 10 -fold higher numbers are seen in AD brains as compared with controls (AD mean $=7.8 \% \pm 1.65$; control mean $=$ $0.80 \% \pm 0.13)$. Changes in endosomal volume as a function of cell area were not significant in $\mathrm{AD}$ and control brains. Magnification in $A, B, 4700 \times$.
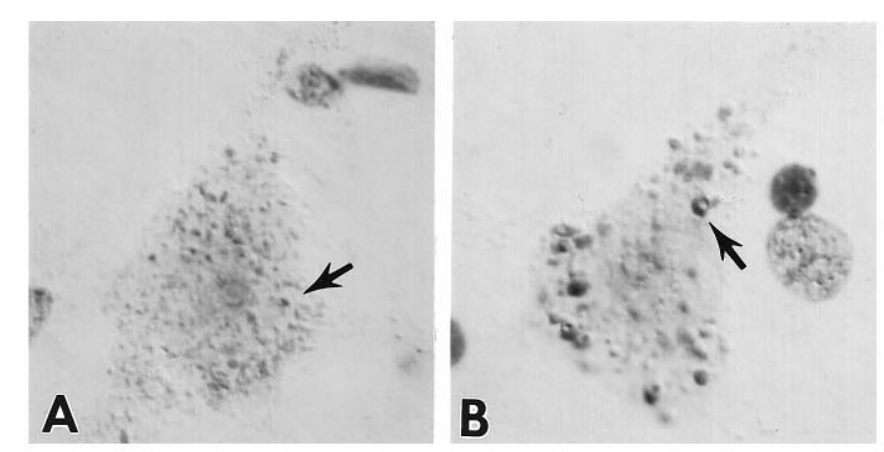

C

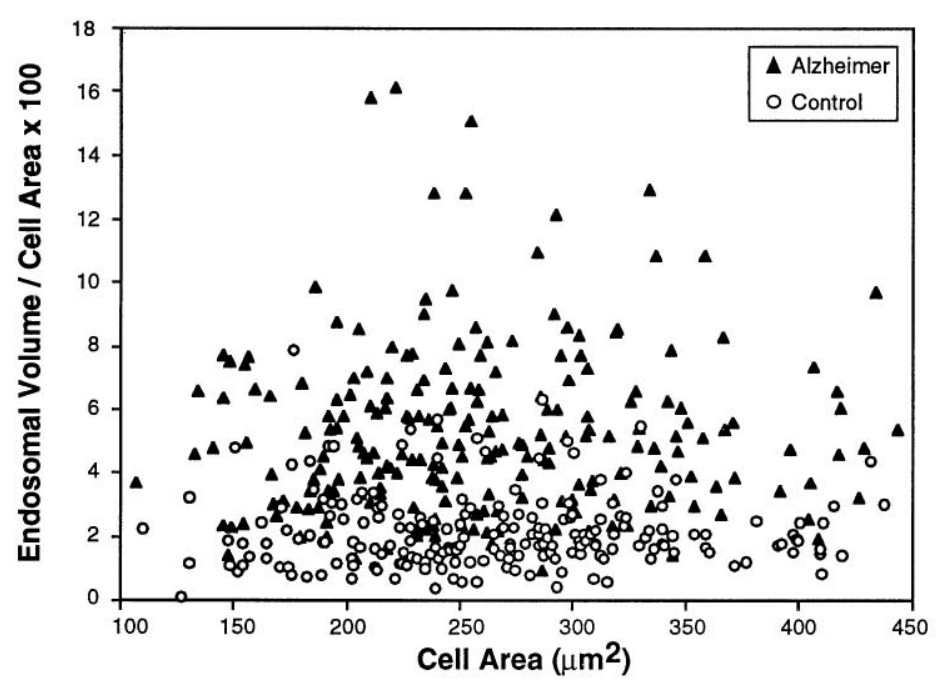

D

Distribution of Endosome Volumes
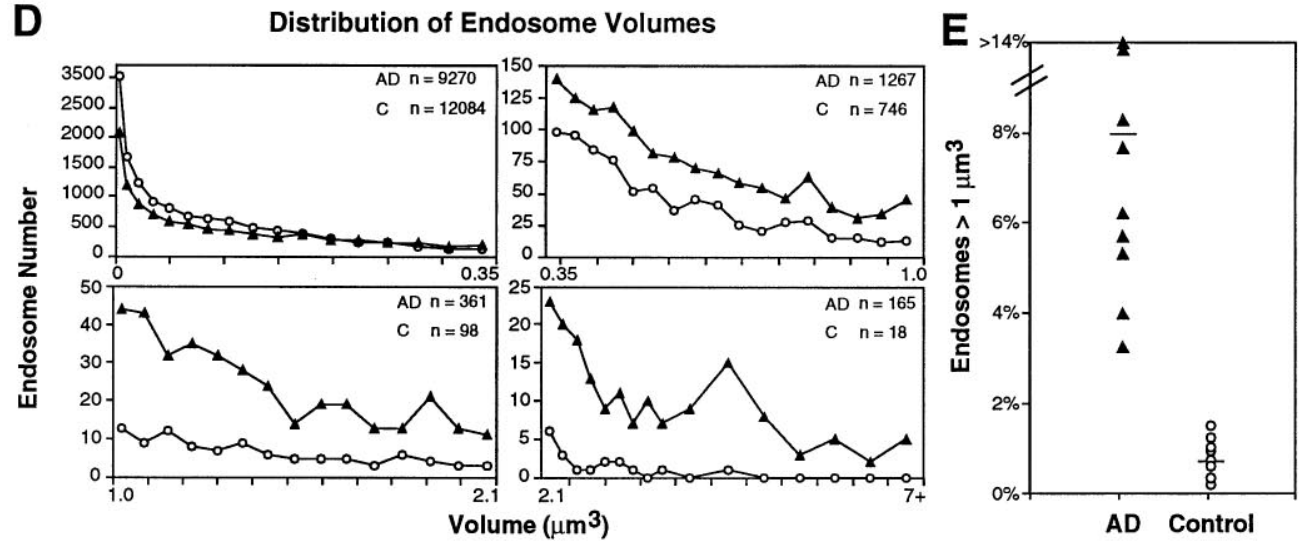

demonstrated that, in most pyramidal neurons in vulnerable regions of AD brains, Cat D and Cat B colocalized within the majority of rab5-positive vacuolar compartments (Fig. 3). Colocalization was evident in $85 \%( \pm 5 \%)$ of neuronal early endosomes of pyramidal neurons in AD brains but in only $25 \%( \pm 5 \%)$ of the neuronal endosomes in control brains. In the AD brains hydrolase was localized more frequently within the larger rab5positive compartments than smaller ones (Fig. 3). As expected, both Cat $\mathrm{D}$ and $\mathrm{Cat} \mathrm{B}$ also were detected in rab5-negative compartments (e.g., late endosomes, mature lysosomes, and lipofuscin).

Human control and $\mathrm{AD}$ brain sections also were doublelabeled with antisera to the proform of Cat D and rab5 by the
ABC technique and two chromogens, DAB and SG, and visualized with bright-field microscopy. We found that in control brains pro-Cat D rarely colocalized with rab5-positive early endosomes, whereas $>50 \%$ of the abnormally large rab5-positive early endosomal profiles in AD brains contained pro-Cat D immunoreactivity (Fig. 4).

\section{MP-R46 content of neurons from affected regions of AD brains is increased}

In pyramidal neurons from human brains, anti-MP-R46 antiserum was located principally in close apposition to the nucleus-a distribution consistent with that of the Golgi apparatus (Fig. 5). This perinuclear distribution was observed in lamina 

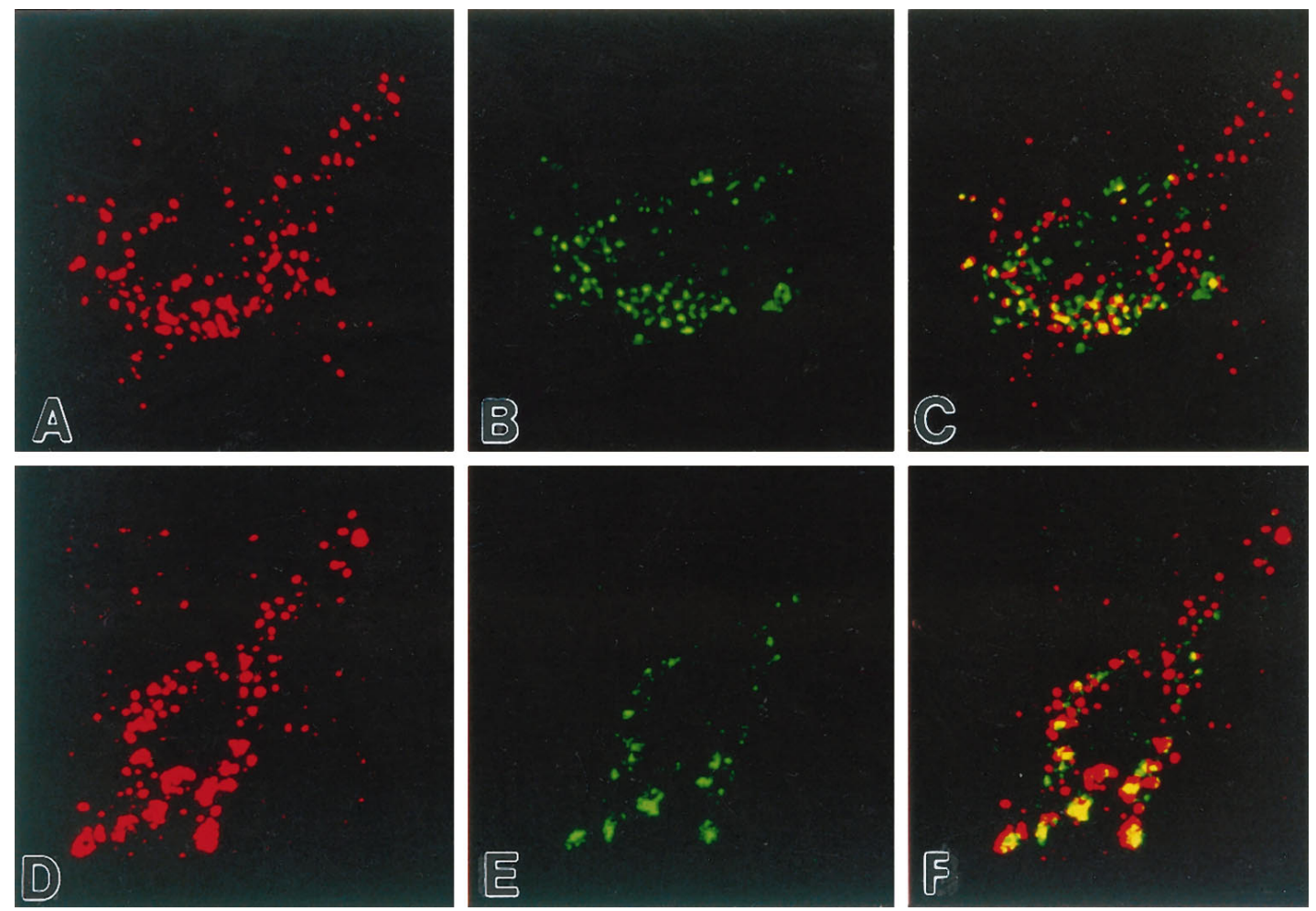

Figure 3. Colocalization of mature proteases in early endosomal compartments of human neurons. Immunofluorescence confocal images of a neocortical pyramidal neuron from control $(A-C)$ and $\mathrm{AD}(D-F)$ brains, using antisera to mature Cat $\mathrm{B}($ red $)$ and rab5 (green), demonstrate that mature lysosomal hydrolases often reside in early endosomes (yellow). The localization of mature protease in early endosomal compartments occurred to a greater extent in neurons in the $\mathrm{AD}$ brains than in controls and more often in the larger endosomal profiles. Both Cat $\mathrm{B}$ and Cat $\mathrm{D}$ (not shown) were present in rab5-positive early endosomes as well as rab5-negative late endosomes, lysosomes, and lipofuscin. Magnification in $A-F, 4000 \times$.

III pyramids of both control and AD brains. We found that the qualitative levels of MP-R46 immunoreactivity were increased in neocortical lamina III neurons of the AD brains, as compared with the levels observed in age-matched control brains. In AD brains anti-MP-R46 antiserum also immunolabeled a population of large vacuolar compartments (Fig. 5), which were not apparent in pyramids from age-matched controls. MP-R46 immunoreactive vacuolar compartments were visualized best in pyramidal neurons exhibiting a lower density of staining. These profiles resembled the ones seen in lamina III pyramids from at-risk AD brain regions labeled with rab5 antiserum (see Figs. 2-4). Both the 215 and $46 \mathrm{kDa}$ MP-Rs are distributed in the trans-Golgi apparatus, endosomes, and lysosomes (Brown et al., 1985; von Figura and Hasilik, 1986; Dahms et al., 1989; Jin et al., 1989). The MP-R215 is enriched in late endosomes and is accepted now as a marker of this compartment, although small amounts have been detected in early endosomes and at the plasma membrane (Fischer et al., 1980; Geuze et al., 1988; Griffiths et al., 1988). Alternatively, MP-R46 is thought most likely to accompany its ligand to early endosomes and the cell surface (Hasilik and von Figura, 1984; Chao et al., 1990). The large MP-R46-positive compartments were similar in size and location to the abnormally large rab5-positive early endosomes. Double-label immunocytochemistry with rab5 and MPR46 antisera could not be performed because these antibodies were both raised in rabbits.

To assess the functional activity of MP-R46 as an alternate mechanism for the delivery of lysosomal proteases to the early endosomal pathway of neurons of at-risk regions of AD brains, we performed semiquantitative morphometric analyses to deter- mine the density of MP-R46-positive compartments in 25 lamina III pyramids from seven AD brains and six age-matched controls (Fig. 5). Total MP-R46 density per neuron in the AD brains was up to twofold higher than the density of the MP-R46 in the age-matched control brains, and the average density was $30 \%$ higher (Student's $t$ test, $p<0.001$; Fig. 5).

\section{DISCUSSION}

\section{Early endosomes in neurons of human brain}

This study is the first to our knowledge to identify and characterize early endosomal compartments in brain in vivo and has revealed a sizable population of early endosomes in normal neurons. The identity of early endosomes in human neurons is based on several lines of evidence. First, these vacuolar compartments were immunolabeled selectively by an antibody directed against rab5, a resident protein of early endosomes and an established marker of this compartment (Parton et al., 1989, 1992; Gorvel et al., 1991; Bucci et al., 1992, 1994; de Hoop et al., 1994; Stenmark et al., 1994). Second, they were not labeled by immunocytochemical markers of other compartments of the E-L pathway, including MP-R215 (late endosomes) and LAMP-2 (lysosomes; our unpublished results), and they contained no lipopigment indicative of lipofuscin (Nixon and Cataldo, 1995; Cataldo et al., 1996). Furthermore, early endosomes predominantly were distributed close to the cell surface and were prominent in both the cell soma and processes, particularly proximal dendrites. This localization pattern is consistent with that observed in a variety of cultured neurons and non-neuronal cells; however, the pattern differed from the perinuclear location of late endosomes and the diffuse cytoplasmic localization of mature 


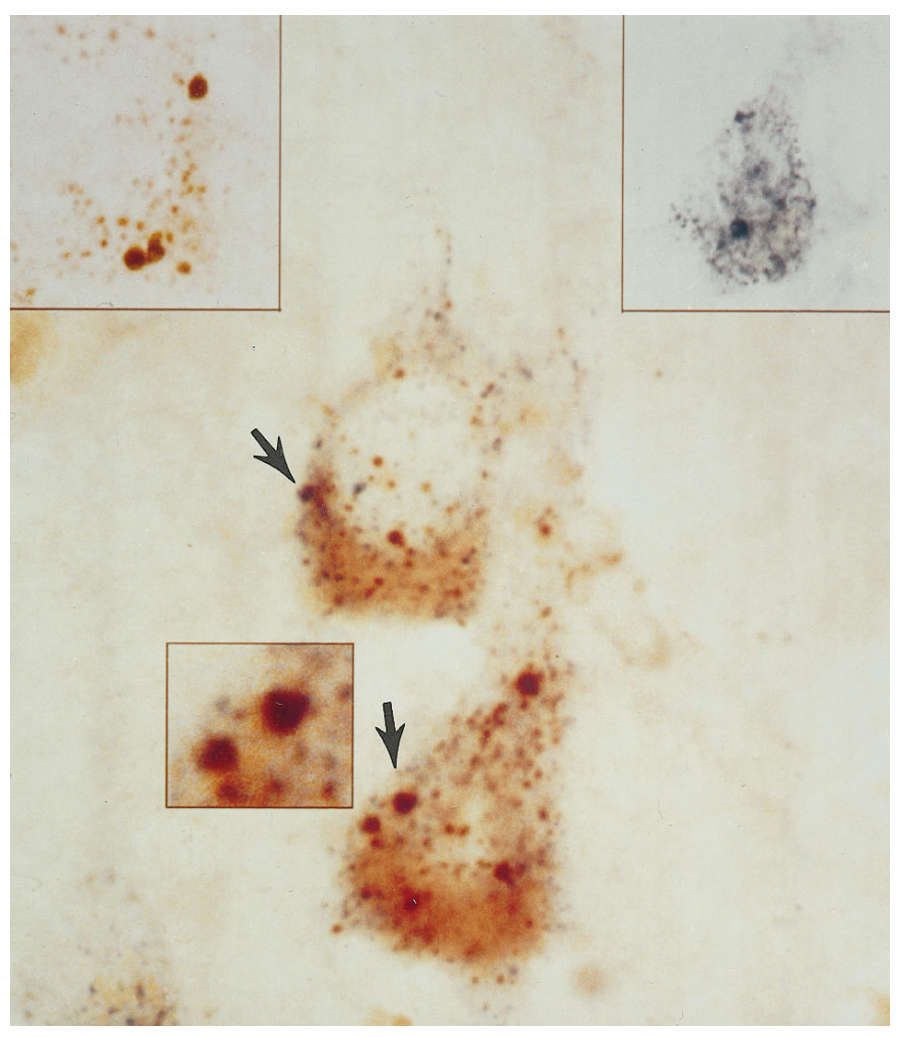

Figure 4. Immature proteases frequently are detected in early endosomes of AD neurons. Double-label immunocytochemical analysis with bright-field microscopy and antisera directed against pro-Cat D (brown left inset) and rab5 (blue, right inset) in this lamina III pyramid from an $\mathrm{AD}$ brain is a representative example of the frequent colocalization of immature proteases in the abnormally large early endosomes (arrows). Pro-Cat $\mathrm{D}$ is also present in a population of smaller immunoreactive vacuolar compartments, which are consistent with late endosomes and are increased in number in AD neurons, as compared with normal controls (see Fig. 1B). Magnification, $4350 \times$; magnification in left and right insets, $3600 \times$; magnification in center inset, $6000 \times$.

lysosomes that reside in both the cell body and processes but predominate in the soma. A percentage of these vacuoles normally contain acid hydrolase, as predicted from other studies (Diment et al., 1989; Casciola-Rosen and Hubbard, 1991; Berg et al., 1995), and this percentage was increased in AD brains. Finally, the sizes of rab5-positive vacuolar compartments in neurons from normal human brains ranged from 100 to $250 \mathrm{~nm}$ in diameter. Each of these characteristics of early endosomes is in agreement with what is known about these compartments from studies of non-neuronal (Parton et al., 1989; Gorvel et al., 1991; Bucci et al., 1992, 1994; Stenmark et al., 1994) and neuronal (Parton et al., 1992; de Hoop et al., 1994) cell lines and primary cultures of neurons (de Hoop et al., 1994).

\section{Increased endocytic activity and cathepsin trafficking to early endosomes in AD}

We found that total endosomal volumes of neurons within laminae III of AD brains were, on average, 2.5-fold larger than normal and that a high proportion of pyramidal cells exhibited these abnormalities. Previous studies have shown that the size of early endosomal compartments reflects the degree of endocytic uptake. Rab5, which regulates the early endocytic pathway by modulating plasma membrane uptake and trafficking and which regulates the fusion of endosomes derived from the plasma membrane (Parton et al., 1989; Gorvel et al., 1991; Bucci et al., 1992, 1994; de Hoop et al., 1994; Stenmark et al., 1994), seems to be a major determinant of this process. Increased rab5 expression stimulates endocytic uptake and expands the size of early endosomes (Gorvel et al., 1991; de Hoop et al., 1994), whereas the expression of mutants defective in rab5 decreases the rate of endocytic uptake (Gorvel et al., 1991; Stenmark et al., 1994). The appearance of abnormally large rab5-positive early endosomes in neurons of at-risk regions of AD brains, therefore, strongly suggests an accelerated rate of endocytosis.

Previously, we showed that pyramidal neurons and other neuronal populations affected in AD contained abnormally high numbers of late endosomal and lysosomal compartments (Cataldo et al., 1994, 1996). The major acid hydrolase-containing compartments in the cell, late endosomes and lysosomes, are associated with terminal processing of substrates that arrive by the endocytic pathway, by autophagy (Gordon et al., 1992), or by direct scavenging of proteins from the endoplasmic reticulum to lysosomes (Noda and Farquhar, 1992). Increased numbers of these organelles could, therefore, reflect the upregulation of one or both of these cellular-processing pathways. Our results demonstrate that increased activity in the early endocytic pathway in sporadic AD is likely to account, in part, for the massive activation of the lysosomal system. Consistent with a more active rate of endocytosis, we observed that the gene expression of Cat D and Cat B is upregulated (Cataldo et al., 1995) and that greater amounts of these proteases are being trafficked to neuronal early endosomes in AD brain. That acid hydrolases of many types are present in greater amounts in lysosomes of affected neurons in AD brain (Cataldo et al., 1991) raises the possibility that some of these enzymes also may be represented more highly in early endosomes in AD. Early endosomes, unlike other compartments of the E-L pathway, normally contain low levels of cathepsins (Diment et al., 1989; Casciola-Rosen and Hubbard, 1991; Berg et al., 1995). In vitro studies (Ludwig et al., 1991) have shown that the newly synthesized lysosomal hydrolases can be trafficked to the early endosome, but the trafficking mechanisms have yet to be elucidated. The presence of active proteases and perhaps other hydrolases in early endosomes provides a basis for partial proteolytic processing of endocytosed materials within these organelles, as shown for various substrates (Diment et al., 1989; Casciola-Rosen and Hubbard, 1991; Berg et al., 1995). The increased detection of the proteases Cat D and Cat B in early endosomes observed in this study, together with the findings of much larger early endosomes in pyramidal neurons of AD brains, indicates that trafficking of these proteases to this compartment is increased and supports the notion that proteolytic activity within early endosomes is more active.

In response to increased endocytic uptake, an increased demand for hydrolases in early endosomes of neurons within affected regions of AD brains may activate alternative mechanisms of enzyme delivery to this compartment. The trafficking of lysosomal hydrolases to both early and late endosomes is compatible with the intracellular distributions of the 215 and $46 \mathrm{kDa}$ MP-Rs (Pfeffer, 1987; Geuze et al., 1988; Griffiths et al., 1988; Bleekemolen et al., 1989). Delivery to late endosomes or lysosomes via the $215 \mathrm{kDa}$ MP-R or to early endosomes/cell surface or lysosomes via the $46 \mathrm{kDa} \mathrm{MP}-\mathrm{R}$ may be favored, depending on cellular alterations that promote different transport routes (see Chao et al., 1990). We observed that levels of MP-R46 immunoreactivity are increased markedly in pyramidal neurons of lamina III of the neocortex of AD brains, as compared with aged con- 

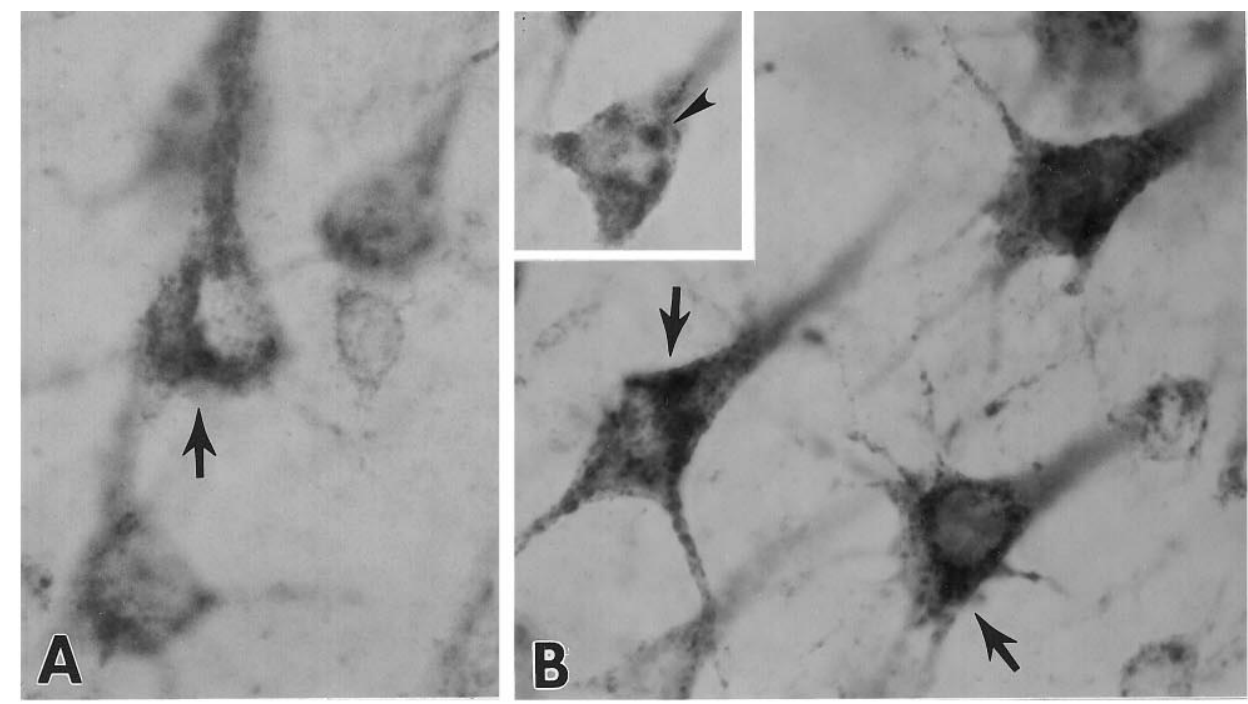

\section{MP-R 46 Immunoreactivity AD vs. Control PFC-Lamina III}

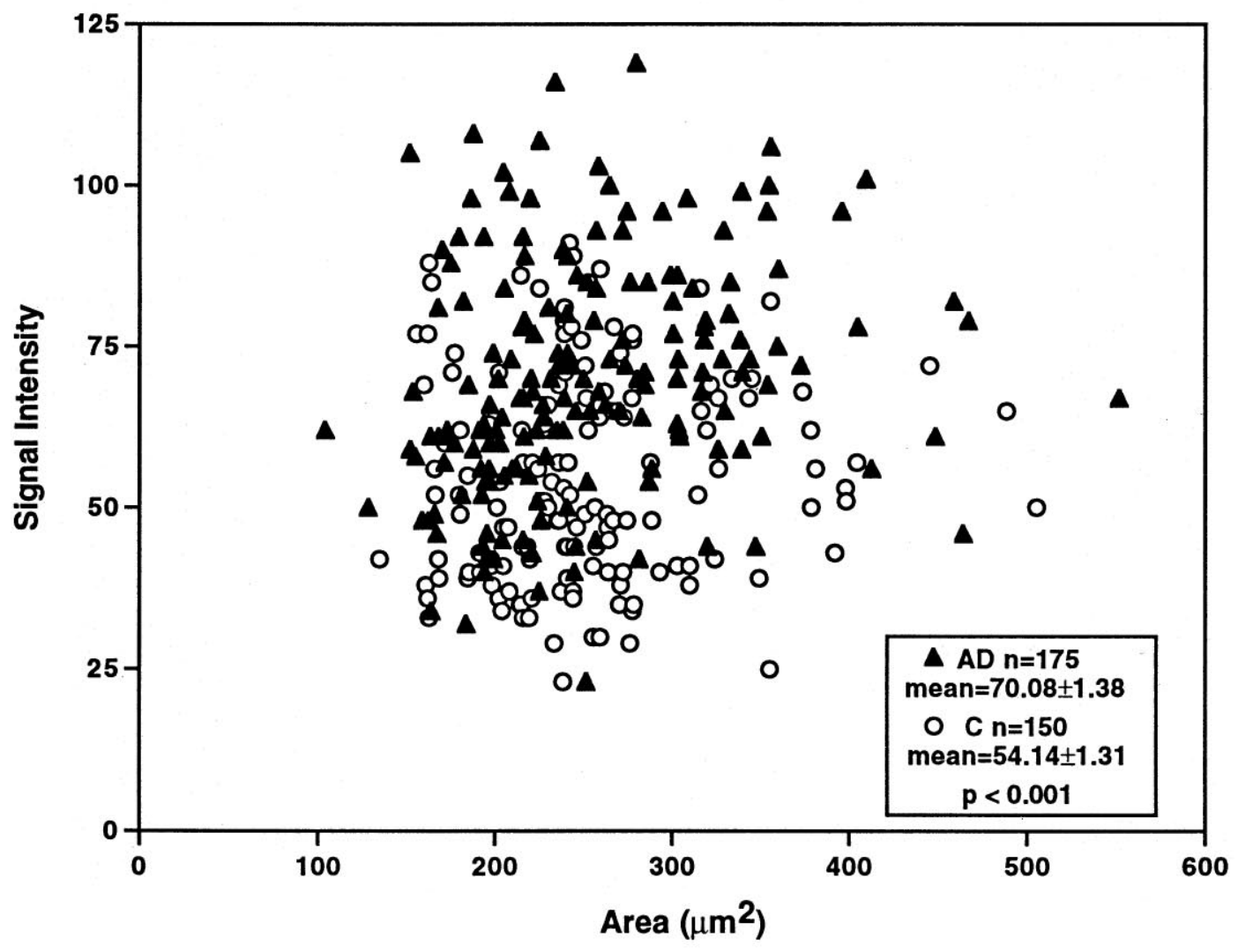

Figure 5. Levels of MP-R46 are elevated in neurons of AD brains. Immunocytochemical studies using antibody directed against MP-R46 show increased levels of this receptor (arrows) in lamina III neurons in the AD brains $(B)$ than in controls $(A)$. (The cells in $A$ range in optical density from 57 to 67 , control mean $=54.14 \pm 1.31$; those in $B$ range in optical density from 71 to 86 , AD mean $=70.80 \pm 1.38 ; p<0.001$. Percentage difference above the mean optical density was equivalent for neurons in $A$ vs $B$.) In AD brains displaying lower levels of immunostaining, MP-R46 immunolabeling could be visualized clearly within large vacuolar profiles $(B$, inset, arrowhead) that resembled the abnormally large rab5-positive early endosomal profiles. Semiquantitative morphometric analysis from sections of the prefrontal cortex revealed that cortical pyramids in laminae III of the AD brains ( filled triangles) exhibit increased MP-R46 densities per cross-sectional area as compared with age-matched controls (open circles). Magnification in $A, B, B$ inset, $3600 \times$. 
trols. This receptor normally plays a less dominant role than the $215 \mathrm{kDa}$ MP-R in the transport of newly synthesized acid hydrolases to late endosomes and lysosomes (Stein et al., 1987b; Dahms et al., 1989) and mediates the transport of endogenous lysosomal enzymes to the plasma membrane and early endosomes but, unlike MP-R215, does not mediate the endocytosis of secreted hydrolase (Stein et al., 1987b; Dahms et al., 1989), which is believed to be the usual route of arrival of hydrolases residing in endosomes. The increase in content of MP-R46 in affected neuronal populations suggests that trafficking pathways are activated that assist in the delivery of lysosomal hydrolases, including the proforms of these hydrolases, to early endosomes. This would be expected to promote an earlier and more efficient processing of substrates arriving to early endocytic compartments at increasingly rapid rates in affected neurons in AD.

Various antecedent events linked to the etiology and progression of AD could lead to the need for increased endocytic activity in neurons of at-risk regions of AD brains. These potentially important events include accelerated membrane turnover/repair resulting from cumulative membrane damage caused by aging, genetic, chemical and oxidative factors (Nixon and Cataldo, 1994), alterations in membrane function or stability because of genetic or chemical alterations of APP, and other membrane proteins accompanying AD (Chartier-Harlin et al., 1991; Terry et al., 1991; Levy-Lahad et al., 1995; Sherrington et al., 1995). ApoE, another critically important molecule in AD pathogenesis (Roses, 1995), is not synthesized in neurons but is taken up by them, particularly during cell injury (Mahley, 1988). In Alzheimer brains increased levels of ApoE have been demonstrated in otherwise normal-appearing neurons of at-risk brain regions and the same cell populations that display early E-L system alterations (Einstein et al., 1995), consistent with increased uptake of ApoE and its subsequent trafficking through the E-L system. More importantly, the increased, and possibly altered, processing of ApoE through this pathway may be related directly to greater levels of neuronal toxicity of the $22 \mathrm{kDa}$ proteolytic fragment of the ApoE-e4 isoform versus the ApoE-e3 isoform (Crutcher et al., 1996).

\section{Implications for $\boldsymbol{\beta}$-amyloidogenesis and pathogenesis in AD}

Previous studies of cultured cell lines have implicated both the secretory (Busciglio et al., 1993; Morato and Mayor, 1993; Araki et al., 1994) and endocytic (Haass et al., 1992; Nordstedt et al., 1993; Koo and Squazzo, 1994; Refolo et al., 1995) pathways in APP processing and $A \beta$ generation. The relative contribution of these two pathways to $\mathrm{A} \beta$ production is altered by the APP mutation that causes early-onset AD (Citron et al., 1992; Suzuki et al., 1994). Involvement of the endocytic pathway in constitutive APP processing and $\mathrm{A} \beta$ production is supported by (1) the presence of the consensus motif, NPTY, on the C terminus of APP, a signal triggering receptor-mediated internalization from the cell surface to endosomes (Chen et al., 1990); (2) the detection of APP and APP fragments in clathrin-coated vesicles (Nordstedt et al., 1993; Marks et al., 1994; Sapirstein et al., 1994); and (3) the ability of treatments that reduce APP internalization to decrease $\mathrm{A} \beta$ release in non-neuronal cell cultures (Koo and Squazzo, 1994).

The neuronal endocytic abnormalities we observed in the brains of Alzheimer patients now provide direct neuropathological support for a mechanism of accelerated $\beta$-amyloidogenesis in sporadic $\mathrm{AD}$, which is also consistent with the foregoing data on the endo- cytic pathway in cultured cell systems (Haass et al., 1992; Nordstedt et al., 1993; Koo and Squazzo, 1994; Refolo et al., 1995). The persistent upregulation of endocytosis seen in pyramidal neurons of Alzheimer brain, by itself, implies an abnormal stimulation of usual endocytic events that should include APP processing and normal $\mathrm{A} \beta$ generation. A further acceleration of APP processing is expected if, as we observed, the trafficking to endosomes of appropriate proteases is increased abnormally. In this regard, one of the cathepsins that we monitored in this study, Cat D, has $\beta$ and $\gamma$ secretase activity toward model peptides and/or recombinant APP (Dreyer et al., 1994; Evin et al., 1995; Higaki et al., 1995; Chevallier et al., 1996). Other cathepsins also indirectly influence $\mathrm{A} \beta$ formation (Sahasrabudhe et al., 1993; Bernstein and Wiedanders, 1994; Munger et al., 1995). The identification of specific hydrolases involved in constitutive $\mathrm{A} \beta$ production, however, is still not definitive. Whether or not the cathepsins are normally responsible for $\mathrm{A} \beta$ production, the possibility may be raised by our studies that, under pathological circumstances, proteases not normally involved in constitutive $\mathrm{A} \beta$ formation become abnormally routed to a cellular compartment within which they now may contribute directly or indirectly to $\mathrm{A} \beta$ production. The identification of proteases that might become APP secretases under a specific pathological condition would require the analysis of cell systems in which that condition is modeled appropriately. Although these effects on endocytosis could be a consequence of $\beta$-amyloid deposition rather than a cause, chromosome 14 mutations leading to AD are associated with high levels of $\beta$-amyloid deposition, but no changes in the appearance of endosomes (A. Cataldo and R. Nixon, unpublished results), consistent with the existence of multiple pathways for $\mathrm{A} \beta$ production and evidence that increased $\beta$-amyloidogenesis in some forms of familial AD may occur by routes other than the endosomal pathway (Haass et al., 1995; Thinakaran et al., 1996).

Enhanced endocytosis is expected to influence ApoE internalization and function, a prediction consistent with the observation of elevated ApoE immunoreactivity in pyramidal neurons in AD. Because ApoE is not synthesized appreciably in neurons, intracellular uptake is critical, and early endosomes are among the few intracellular sites in which ApoE has the opportunity to interact extensively with APP and its cleaved derivatives (Crutcher et al., 1996). Evidence that ApoE isoforms have differential binding affinities for $\mathrm{A} \beta$ and may serve, with varying degrees of effectiveness, as pathological chaperones in A $\beta$ fibrillogenesis (Wisniewski et al., 1994) is another example of how the endocytic pathway represents a crossroad in which etiological factors in $\mathrm{AD}$ pathogenesis converge.

\section{REFERENCES}

Araki W, Kunishita T, Takahashi K, Ikeda S, Tabina T (1994) Demonstration of amyloid $\beta$-protein secretion in a mouse neuronal cell line. Neurosci Lett 167:125-127.

Berg T, Gjoen T, Bakke O (1995) Physiological functions of endosomal proteolysis. Biochem J 307:313-326.

Bernstein HG, Wiedanders B (1994) An immunohistochemical study of cathepsin E in Alzheimer-type dementia brains. Brain Res 667:287-290.

Bleekemolen JE, Stein M, von Figura K, Slot JW, Geuze HJ (1988) The two mannose 6-phosphate receptors have almost identical subcellular distributions in U937 monocytes. Eur J Cell Biol 47:366-372.

Brown WJ, Goodhouse J, Farquhar MG (1985) Mannose 6-phosphate receptors for lysosomal enzymes cycle between the Golgi complex and endosomes. J Cell Biol 103:1235-1247.

Bucci C, Parton RG, Mather IH, Stunnenberg H, Simons K, Hoflack B, Zerial B (1992) The small GTPase rab5 functions as a regulatory factor in the early endocytic pathway. Cell 70:715-728. 
Bucci C, Wandinger-Ness A, Lutcke A, Chiariello M, Bruni CB, Zerial M (1994) Rab5a is a common component of the apical and basolateral endocytic machinery in polarized epithelial cells. Proc Natl Acad Sci USA 91:5061-5065.

Busciglio J, Gabudza DH, Matsudaira P, Yanker BA (1993) Generation of $\beta$-amyloid in the secretory pathway in neuronal and non-neuronal cells. Proc Natl Acad Sci USA 90:2092-2096.

Casciola-Rosen LA, Hubbard AL (1991) Hydrolases in intracellular compartments of rat liver cells. Evidence for selective activation and/or delivery. J Biol Chem 266:4341-4347.

Cataldo AM, Thayer CY, Bird ED, Wheelock TR, Nixon RA (1990) Lysosomal proteinase antigens are prominently localized with senile plaques of Alzheimer's disease: evidence for a neuronal origin. Brain Res 513:181-192.

Cataldo AM, Paskevich PA, Kominami E, Nixon RA (1991) Lysosomal hydrolases of different classes are abnormally distributed in Alzheimer brain. Proc Natl Acad Sci USA 88:10998-11002.

Cataldo AM, Hamilton DJ, Nixon RA (1994) Lysosomal abnormalities in degenerating neurons link neuronal compromise to senile plaque development in Alzheimer disease. Brain Res 640:68-80.

Cataldo AM, Barnett JL, Berman SA, Li J, Quarless S, Bursztajn S, Lippa C, Nixon RA (1995) Gene expression and cellular content of cathepsin D in Alzheimer's disease brain: evidence for early upregulation of the endosomal/lysosomal system. Neuron 14:671-680.

Cataldo AM, Hamilton DJ, Barnett JL, Paskevich PA, Nixon RA (1996) Properties of the endosomal-lysosomal system in the human central nervous system: disturbances mark most neurons in populations at risk to degenerate in Alzheimer's disease. J Neurosci 16:186-199.

Chao HH, Waheed A, Pohlmann R, Hille A, von Figura K (1990) Mannose 6-phosphate receptor-dependent secretion of lysosomal enzymes. EMBO J 9:3507-3513.

Chartier-Harlin M-C, Crawford F, Houlden H, Warren A, Hughes D, Fidani L, Goate A, Rossor M, Roques P, Hardy J, Mullan M (1991) Early-onset Alzheimer's disease caused by mutations at codon 717 of the $\beta$-amyloid precursor protein gene. Nature 353:844-846.

Chen WJ, Goldstein JL, Brown MS (1990) NPXY, a sequence often found in cytoplasmic tails, is required for coated pit-mediated internalization of the low-density lipoprotein receptor. J Biol Chem 265:3116-3123.

Chevallier N, Murambaud P, Vizzavona J, Baur CP, Spillantini M, Fulcrand P, Martinez J, Goedert M, Vincent JP, Checler F (1996) Inhibitors of cathepsin D block $\beta$-secretase link cleavage in human cells. Neurobiol Aging 17:381.

Citron M, Oltersdorf T, Haass C, McConlogue L, Hung AV, Seubert P, Vigo-Pelfrey C, Lieberburg I, Selkoe D (1992) Mutation of the $\beta$-amyloid precursor protein in familial Alzheimer's disease increases $\beta$-protein production. Nature 360:672-674.

Crutcher KA, Tolar M, Harmony JAK, Marques M (1996) Apolipoprotein E-derived $22 \mathrm{kDa}$ fragment neurotoxicity: a new pathophysiological mechanism in Alzheimer's disease. Neurobiol Aging 17:5155.

Dahms NM, Lobel P, Kornfeld S (1989) Mannose 6-phosphate receptors and lysosomal enzyme targeting. J Biol Chem 264:12115-12118.

de Hoop MJ, Huber LA, Stenmark H, Williamson E, Zerial M, Parton RG, Dotti CG (1994) The involvement of the small GTP-binding protein rab5a in neuronal endocytosis. Neuron 13:11-22.

Diment S, Martin KJ, Stahl PD (1989) Cleavage of parathyroid hormone in macrophage endosomes illustrates a novel pathway for intracellular processing. J Biol Chem 264:13403-13406.

Dreyer RN, Bausch KM, Fracasso P, Hammond LJ, Wunderlich D, Wirak DO, Davis G, Brini CM, Buckholz TM, Konig G (1994) Processing of the pre- $\beta$-amyloid protein by cathepsin D is enhanced by a familial Alzheimer's disease mutation. Eur J Biochem 224:265-271.

Einstein G, Bautista P, Patel V, Kenna M, Melone L, Fader R, Karson K, Sauders A, Hulette C, Roses A, Schmechel D (1995) Does ApoE immunoreactivity mark vulnerable neurons in Alzheimer's disease? Alzheimer Res 1:22.

Evin E, Cappai R, Li QX, Culvenor JG, Small DH, Beyreuther K, Masters CL (1995) Candidate $\gamma$-secretases in the generation of the carboxyl terminus of the Alzheimer's disease $\beta A 4$ amyloid: possible involvement of cathepsin D. Biochemistry 34:14185-14192.

Fischer HD, Gonzalez-Noriega A, Sly WS, Morre DJ (1980) Phosphomannosyl-enzyme receptors in rat liver: subcellular distribution and role in intracellular transport of lysosomal enzymes. J Biol Chem 255:9608-9615.

Geuze HJ, Stoorvogel W, Strous GJ, Slot JW, Bleekemolen JE, Mellman
I (1988) Sorting of mannose 6-phosphate receptors and lysosomal membrane proteins in endocytic vesicles. J Cell Biol 107:2491-2501.

Gordon PB, Hoyvik H, Seglen PO (1992) Prelysosomal and lysosomal connections between autophagy and endocytosis. Biochem $\mathrm{J}$ 283:361-369.

Gorvel J-P, Chavrier P, Zerial M, Gruenberg J (1991) Rab5 controls early endosome fusion in vitro. Cell 64:915-925.

Griffiths G, Hoflack B, Simons K, Mellman I, Kornfeld S (1988) The mannose 6-phosphate receptor and the biogenesis of lysosomes. Cell 52:329-341.

Haass C, Kao EH, Mellon A, Hung AY, Selkoe DJ (1992) Targeting of cell surface $\beta$-amyloid precursor protein to lysosomes: alternative processing into amyloid-bearing fragments. Nature 357:500-503.

Haass C, Lemere CA, Capell A, Citron M, Seubert P, Schenk D, Lannfelt L, Selkoe DJ (1995) The Swedish mutation causes early-onset Alzheimer's disease by $\beta$-secretase cleavage within the secretory pathway. Nat Med 1:1291-1296.

Hasilik A, von Figura K (1984) Processing of lysosomal enzymes in fibroblasts. In: Lysosomes in biology and pathology, Vol 7 (Dingle JT, Dean RT, Sly W, eds), pp 3-16. Elsevier: North Holland.

Higaki J, Quon D, Zhong Z, Cordell B (1995) Inhibition of $\beta$-amyloid formation identifies proteolytic precursors and subcellular site of catabolism. Neuron 14:651-659.

Jin M, Sahagian GG, Snider MD (1989) Transport of surface mannose 6-phosphate receptor to the Golgi complex in cultured human cells. J Biol Chem 264:7675-7680.

Koo EH, Squazzo SL (1994) Evidence that production and release of amyloid $\beta$-protein involves the endocytic pathway. J Biol Chem 269:17386-17389.

Levy-Lahad E, Wasco W, Poorkaj P, Romano DM, Oshima J, Pettingwell WH, Yu CE, Jondro PD, Schmidt SD, Wang K (1995) Candidate gene for the chromosome 1 familial Alzheimer's disease locus. Science 269:973-977.

Ludwig T, Griffiths G, Hoflack B (1991) Distribution of newly synthesized lysosomal enzymes in the endocytic pathway of normal rat kidney cells. J Cell Biol 115:1561-1572.

Mahley RW (1988) Apolipoprotein E: cholesterol transport protein with expanding role in cell biology. Science 240:622-630.

Marks N, Berg MJ, Chi LM, Choi J, Durrie R, Swistok J, Makofske RC, Danho W, Sapirstein VS (1994) Hydrolysis of amyloid precursor protein-derived peptides by cysteine proteinases and extracts of rat brain clathrin-coated vesicles. Peptides 15:175-182.

Mirra SS, Heyman A, Mc Keel D, Sumi SM, Crain BJ, Brownlee LM, Vogel FS, Hughes JP, Van Belle G, Berg L (1991) The consortium to establish a registry for Alzheimer's disease (CERAD). Part II. Standardization of the neuropathologic assessment of Alzheimer's disease. Neurology 41:479-486.

Morato E, Mayor Jr F (1993) Production of the Alzheimer's $\beta$-amyloid peptide by C6 glioma cells. FEBS Lett 336:275-278.

Munger JS, Haass C, Lemere CA, Shi GP, Wong WS, Teplow DB, Selkoe DJ, Chapman HA (1995) Lysosomal processing of amyloid precursor protein to $\mathrm{A} \beta$ peptides: a distinct role for cathepsins. Biochem $\mathrm{J}$ 311:299-305.

Nadimpalli SK, Schmidt B, von Figura K, Hille A (1991) Antibodies against cytoplasmic tail can differentiate between the quaternary forms of the $M_{\mathrm{r}}$ 46,000 mannose 6-phosphate receptor. FEBS Lett 280:61-64.

Nixon RA, Cataldo AM (1993) The lysosomal system in neuronal cell death: a review. Ann NY Acad Sci 679:87-109.

Nixon RA, Cataldo AM (1994) Free radicals, proteolysis, and the degeneration of neurons in Alzheimer's disease: how essential is the $\beta$-amyloid link? Neurobiol Aging 15:463-469.

Nixon RA, Cataldo AM (1995) The endosomal-lysosomal system of neurons: new roles. Trends Neurosci 18:489-496.

Nixon RA, Marotta CA (1984) Degradation of neurofilament proteins by purified human brain cathepsin D. J Neurochem 43:507-516.

Noda T, Farquhar MG (1992) A non-autophagic pathway for diversion of ER secretory proteins to lysosomes. J Cell Biol 119:85-97.

Nordstedt C, Caporaso GL, Thyberg J, Gandy SE, Greengard P (1993) Identification of the Alzheimer $\beta / \mathrm{A} 4$ amyloid precursor protein in clathrin-coated vesicles purified from PC12 cells. J Biol Chem 268:608-612.

Parton RG, Prydz K, Bomsel M, Simons K, Griffiths G (1989) Meeting of the apical and basolateral endocytic pathways of the Madin-Darby canine kidney cell in late endosomes. J Cell Biol 109:3259-3272. 
Parton RG, Simon K, Dotti CG (1992) Axonal and dendritic endocytic pathways in cultured neurons. J Cell Biol 119:123-137.

Pfeffer S (1987) The endosomal concentration of a mannose 6-phosphate receptor is unchanged in the absence of ligand synthesis. J Cell Biol 105:229-234.

Refolo LM, Sambamurti K, Efthimiopoulos S, Pappolla MA, Robakis NK (1995) Evidence that secretase cleavage of cell surface Alzheimer amyloid precursor occurs after normal endocytic internalization. J Neurosci Res 40:694-706.

Roses AD (1995) Perspective: on the metabolism of apolipoprotein E and Alzheimer's disease. Exp Neurol 132:149-156.

Sahasrabudhe SR, Brown AM, Hulmes JD, Jacobson JS, Vitek MP, Blume AJ, Sonnenberg JL (1993) Enzymatic generation of the amino terminus of the $\beta$-amyloid peptide. J Biol Chem 268:16699-16709.

Sapirstein VS, Durrie R, Berg MJ, Marks N (1994) Amyloid precursor protein is enriched in axolemma and periaxolemmal-myelin and associated clathrin-coated vesicles. J Neurosci Res 37:348-358.

Sherrington R, Rogaev EL, Liang Y, Rogaeva EA, Levesque G, Ikeda M, Chi H, Lin C, Li G, Holman K, Tsuda T, Mar L, Foncin J-F, Bruni AC, Montesi MP, Sorbi S, Rainero I, Pinessi L, Nee L, Chumakov I, Pollen D, Brookes A, Sanseau P, Polinsky RJ, Wasco W, Da Silva HAR, Haines JL, Pericak-Vance MA, Tanzi RE, Roses AD, Fraser PE, Rommens JM, St George-Hyslop PH (1995) Cloning of a gene bearing missense mutations in early-onset familial Alzheimer's disease. Nature 375:754-760.

Stein M, Braulke T, Krentler C, Hasilik A, von Figura K (1987a) 46 kDa mannose 6-phosphate-specific receptor: biosynthesis, processing, subcellular location, and topology. Biol Chem Hoppe Seyler 368:937-947.
Stein M, Zijderhand-Bleekemolen JE, Geuze H, Hasilik A, von Figura K (1987b) $M_{\mathrm{r}}$ 46,000 mannose 6-phosphate-specific receptor: its role in targeting of lysosomal enzymes. EMBO J 6:2677-2681.

Stenmark H, Parton RG, Steele-Mortimer O, Lutcke A, Gruenberg J, Zerial M (1994) Inhibition of rab5 GTPase activity stimulates membrane fusion in endocytosis. EMBO J 13:1287-1296.

Suzuki N, Cheung TT, Cai XD, Odaka A, Otvos Jr L, Eckman C, Golde TE, Younkin SG (1994) An increased percentage of long amyloid $\beta$-protein secreted by familial amyloid $\beta$-protein precursor ( $\beta$ APP717) mutants. Science 264:1336-1340.

Tagawa K, Kunishita T, Maruyama K, Yoshikawa K, Kominami E, Tsuchiya T, Suzuki K, Tabira T, Sugita H, Ishiura S (1991) Alzheimer's disease amyloid $\beta$-clipping enzyme (APP secretase): identification, purification, and characterization of the enzyme. Biochem Biophys Res Commun 177:377-387.

Terry RD, Masliah E, Salmon DP, Butters N, DeTeresa R, Hill R, Hansen LA, Katzman R (1991) Physical basis of cognitive alterations in Alzheimer's disease: synapse loss in the major correlate of cognitive impairment. Ann Neurol 30:572-580.

Thinakaran G, Teplow DB, Siman R, Greenberg B, Sisodia SS (1996) Metabolism of the "Swedish" amyloid precursor protein variant in neuro2a (N2a) cells: evidence that cleavage at the beta-secretase site occurs in the Golgi apparatus. J Biol Chem 271:9390-9397.

von Figura K, Hasilik A (1986) Lysosomal enzymes and their receptors. Annu Rev Biochem 55:167-173.

Wisniewski T, Castano EM, Golabeck A, Vogel T, Frangione B (1994) Acceleration of Alzheimer's fibril formation by apolipoprotein E in vitro. Am J Pathol 145:1030-1035. 